\title{
Social Comics: A Casual Authoring Game
}

\author{
Paul Lapides \\ Ehud Sharlin \\ University of Calgary \\ 2500 University Drive NW, Calgary, Alberta, T2N 1N4, Canada \\ paul.lapides@gmail.com \\ ehud@cpsc.ucalgary.ca \\ Mario Costa Sousa \\ smcosta@ucalgary.ca
}

\begin{abstract}
We present Social Comics, a casual video game that allows players to act in short comic strips that they create. We designed Social Comics to be a fast paced game that engages the audience and players equally, in an effort to adapt it for parties and social gatherings. We motivate Social Comics with a design framework for video games that combines three gameplay elements: sociability, physicality, and authoring. We believe that the combination of these three gameplay elements in video games will allow collocated players to enjoy game experiences that are socially rich, inclusive and creatively empowering. Our paper describes the design and implementation of Social Comics as well as the results of a user study evaluating the game.
\end{abstract}

Computer games, social interaction design, emotive and fun interfaces, group interaction, user-generated game content.

\section{INTRODUCTION}

The video game industry has expanded tremendously in the last decade, an expansion reflected in the gender and age demographics of gamers. The average age of gamers today is 34 years, and 26 per cent of gamers are over 50 years of age. Females now account for 40 percent of all gamers. The stereotype that most gamers are young boys is no longer true. Twenty per cent of gamers are males 17 years or younger, while 33 per cent of gamers are women 18 years or older. Another false stereotype is that video games are isolating activities, but 64 per cent of gamers in the USA play with other gamers in person. Forty eight per cent of parents play games with their children (ESA 2010).

Game systems are offering players more controller options that allow rich physical interaction. The five of the top six best selling console games in 2010 were developed for the Wii (ESA 2010). In 2009 Nintendo released Wii MotionPlus, a hardware expansion to their WiiMote game controller, which enhances its tracking accuracy. 2010 saw the release of the PlayStation Move controller for the PS3 and the Microsoft Kinect controller for the Xbox 360. All three systems focus on games with physical interaction. In the UK, 2010 game unit sales increased $12.2 \%$ for the PS3 and $7.7 \%$ for the Xbox 360 while PC game unit sales fell $16.7 \%$ (ERA 2010). This suggests that physical games are becoming increasingly popular.

The internet has undergone a revolution similar to video games. The emergence of Web2.0 and social media has transformed the way people communicate by allowing anyone with a computer to reach an extremely large audience very quickly. This ability is the result of the widespread use of blogs, video and photo sharing websites and social networking websites. Digital cameras have become almost ubiquitous by appearing on phones and laptops, and being sold individually as inexpensive devices. Digital cameras allow a user to create their own visual content and then to share it with their friends with ease.

In the near future we envision the integration of physical games with social and user-generated media. These games will bring people together and allow us to relate to one another rather than isolate us. Games will be played in casual settings, at social gatherings and parties, and will focus on cooperative instead of competitive gameplay. While people play the game they will be creating content that will be representative of the gaming experience. In the same way that people share photos and videos with each other, so too will we share game experiences.

In this paper we will examine the game design elements that have allowed games to permeate our lives by introducing Social Comics, a casual game that allows players to interactively create comic strips in which they are the main characters (Figure 1). We designed Social Comics with emphasis on social and physical gameplay, as well as on a rich authoring or user generated content creation gameplay element (which to our knowledge is quite 


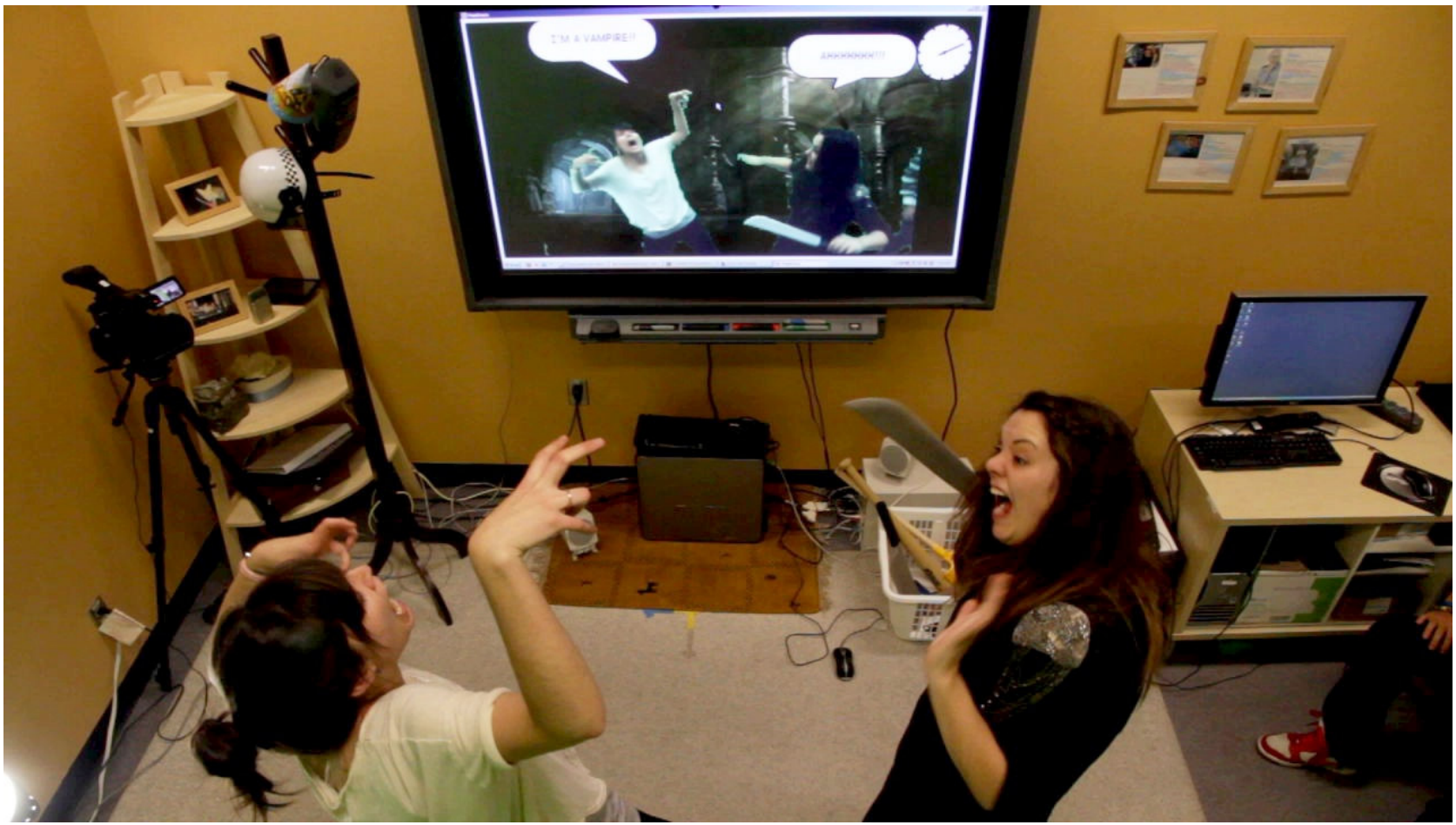

Figure 1: Social Comics gameplay. Hats and props to the left and right of the display, spectators on the right.

unique). We present the design of the game, as well as findings of a thorough user study, and a reflection on the future of the new genre of games that Social Comics represents.

\section{RELATED WORK}

Pervasive and physical games have been studied in the Human-Computer Interaction community for several years. Originally an arcade game, Dance Dance Revolution (DDR) is played by stepping on colour pads in synchrony to scrolling colours on the screen representing dance moves during a song. Participants in a study by Sall and Grinter (2007) used a physical game such as DDR in the home for at least a year. Participants explained that while their initial motivation for purchasing physical games was for exercise, they began to play the games for fun rather than the physical workout. Physical games were referred to as "performances", and people not actively playing began to cheer for the players and became engaged spectators of the game. Participants explained that playing the game without an audience felt "weird" and not as fun. We believe games that fail to engage spectators may indirectly alienate the players themselves and consider spectator engagement as an important thread in the games design.

Similarly to Sall and Grinter's study, Voida and Greenberg (2009) report that gamers feel "Ionely" when playing alone. In addition to the company provided by other players, social interaction such as teamwork or competition emerges between players. Voida and Greenberg also report that while online multiplayer games surround the player with other remote gamers, the game is still played in isolation.

The recent integration of advanced motion sensors and cameras with game consoles like the Microsoft Kinect and PlayStation Eye has allowed the design of more immersive physical games. Yoostar allows players to act in famous movie scenes as one of the principal characters (Yoostar 2011). The game is structured similarly to karaoke. The player stands in front of a camera and their image is composted into the movie scene, replacing an actor entirely. Lines from the movie script appear above the composite, and the player reads them as if they were the character, or makes up their own dialogue. The composited clip can then be uploaded to the player's social networking site for friends to watch. Conceptually Yoostar is very close to the design approach that motives the games we design, combining social, physical and authoring gameplay elements. One important difference is that Yoostar is a single player game (as far as we know). This may limit the potential for social group interaction.

Rowland et al. (2010) present Automics, an automatic photo-story generation prototype implemented in amusement parks. The system combines photos taken by fair-goers with photos taken by the automatic camera systems installed in 
many amusement park rides. The photos are assembled into a comic strip following a specific template for each ride and can be taken home by the customer. While the system creates a comic strip of the experience, the central activity for the user still seems to be the amusement park ride, not the generation of a photo-story.

\section{DESIGN FRAMEWORK}

Our game design framework is based on combining three gameplay elements which we believe can create more engaging and enjoyable collaborative games: sociability, physicality and authoring of content.

\subsection{Sociability}

We approach sociability by identifying that players should be playing the game in each other's presence. Online gaming does not offer the rich non-verbal communication that collocated gaming does. Also, the anonymity and physical separation of remote players can often lead to aggressive behaviour and trolling with no consequences. However, we argue that simply being collocated is not enough to classify the game experience as a social one. Most games have a maximum of four players, and while those playing may be sharing a social experience, there is the possibility that those who are not actively playing but instead watching the gameplay are being socially neglected. This gives rise to the notion of a game spectator, a person who is not playing but is still being engaged by the game and the people playing it. We believe that good gameplay design should explicitly account for inclusive engagement of the nonplayer: the game spectator.

\subsection{Physicality}

While traditional handheld controllers offer very accurate and explicit control of the game, they are often complex and require time to learn to use effectively. Including physical entities in the gameplay allows players to start playing the game with a much faster learning curve. We envision ordinary objects being used as game entities by taking advantage of their physical affordances. For example, an ordinary ball may be represented in the game as an object and can be thrown between players. The players are not throwing a virtual ball, but a real one that has become a game controller.

\subsection{Authorship}

We see authorship in games as inclusion of gameplay goals that target the creation of new content. Authorship within games will be directed at content that is a representation of the game experience and can be shared with others. Such content can be photos, videos, audio, or a combination of these media. It is important not to confuse authorship with customisation, which may not be sharable and does not represent the game experience to the same extent. One can argue that within customisation the player is creating some unique content. In these cases, it is fair to argue that customisation is only a secondary goal of the game. Customisation may give the player a different type of car to race or a unique weapon, but the central gameplay themes are still racing and shooting, not creating cars or new weapons. We believe it is important that the authorship gameplay be a fun and engaging experience. We also believe it is important that the authoring experience and outcomes will be shared with collocated spectators, as well as with non-players who may wish to view the content later.

\section{SOCIAL COMICS}

We designed and implemented a game called Social Comics that combines the authoring element in conjunction with social and physical gameplay (Social Comics' design is based on an earlier concept which was brainstormed in Lapides (2010)) Social Comics is played in a home theatre setting, similar to the setting in which console games are played today, and is designed to be played with a group of people. Social Comics allows players to create and participate in interactive comic strips, acting out physically the textual content of the strips, and in the process becoming the strips' main characters.

\subsection{Gameplay}

Players stand in an open space in front of a display that may be a wall-mounted television, a computer monitor or a laptop. Above the display is a webcam pointed directly at the players. The video image from the camera is horizontally flipped and displayed to the players, who now see a mirror image of themselves and their surroundings on the display in real-time. Behind the players is a large green fabric hanging on a wall or from the ceiling that acts as a green screen. The area directly between the display and green screen is referred to as the acting space, the place where players pose for the comic. The image from the camera is processed using a chroma-key filter so that the green screen is digitally replaced with a background image (Chaplin 1993). In our implementation, the display is a large wall-mounted television, and a large green screen fabric is hung four meters away from the display, creating a spacious acting space enclosure.

To the side of the acting space there is a couch and chairs where spectators may sit and watch the players. The players can use a variety of physical 


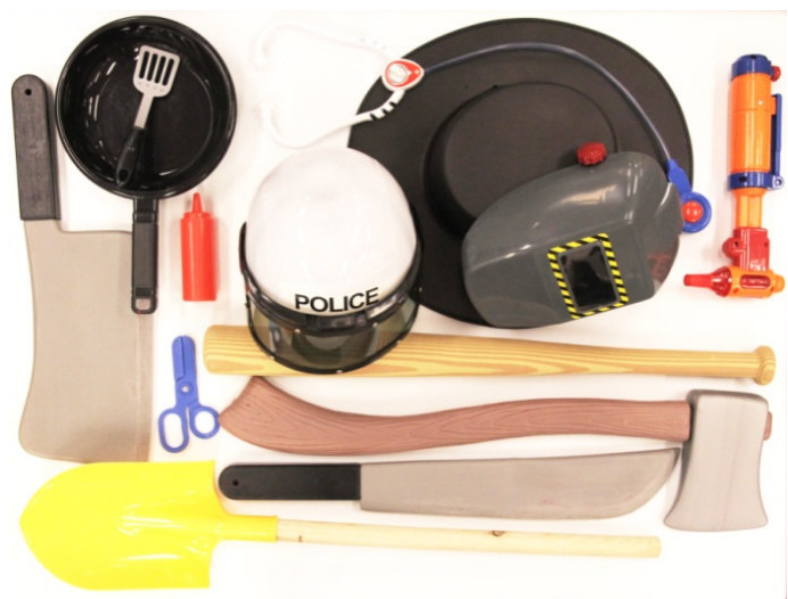

Figure 2: Props used in Social Comics.

objects as props in the game, selecting from a dedicated set of inexpensive toys or hats arranged next to the acting space (Figure 2).

The game is played by at least two players who create a comic strip one panel at a time in serial succession. First panel one is created, then two, then three, etc. The panels have two speech bubbles each with a short line of text that are currently prepared a priori by the game designer. These speech bubbles are overlaid above the image of the players, near the top of the display. The speech bubbles are statically positioned, and each has a short arrow that descends slightly, as in a real comic strip (Figures 1 and 3 ). The players have a limited amount of time to create each panel (20 seconds) shown on the display by a timer that counts down to zero. The game starts with the first panel of the comic appearing on the display, and with commencing of the timer countdown.

Before the timer reaches zero the players must read the text in the speech bubbles, select any props they want to use and pose with the props under their speech bubble. When the timer reaches zero the image of the players, props and background from the camera combined with the green screen background and speech bubbles becomes one of the panels in the comic. The timer is reset and the next panel is immediately started, including new text appearing in the speech bubbles. When the final panel is finished, all of the panels are combined together into a single comic strip image that is saved to the hard drive (Figure 3). The players can review the final comic strip outcome and move on to playing a new comic when they are finished.

The text that is shown in the speech bubbles refers to the comic story and these lines of dialogue drive the game for the two players. The text is carefully prepared by the game designer so that it provides an overall arc to the story while being intentionally vague to allow the players to interpret it in various ways or to ignore it outright, supporting a free gameplay experience. Each comic story has an associated background image that is related to the text and provides context to the players. For example, if the comic story is about sports, the background image is of a sports arena.

There are no restrictions on how to play the game. The players are free to pose in any way they like, ask the spectators for suggestions or even include their friends in the comic strip. Social Comics uses no controllers and players must only act and use props to play the game, making it extremely simple to learn and to play.

\subsection{Pilot Studies}

Two structured pilot studies were conducted to evaluate different aspects of Social Comics including gameplay features, game content, and the evaluation approach. Beyond the two pilot studies the game was also used several times for public demonstrations and as an actual party game, all unstructured. We report the structured pilot studies below, but it is worthwhile to reflect on the non-structured experiences as well. While these were not directed at gaining explicit measures, they served to initially verify that the game was fun to play.

The first structured pilot involved four participants (three female, one male) and addressed gameplay issues such as the time allotted per panel, the position of the comic bubbles and green screen, the comic text and stories, the comic review features, the dynamics of four people playing the game and language issues in the questionnaire and interview questions. The second pilot involved two participants (one female, one male) and mostly explored the speech bubble text and their fitting to the background images.

Several issues were identified from the first pilot. The participants sat on a large couch that was situated in the middle of the acting space, regardless of who was actively playing. This resulted in difficulties to distinguish between players and spectators, and less space was available for posing. Following this pilot session the couch was replaced with chairs and moved to the side of the acting space to give the active players more room to move around while posing. This change also helped distinguish between players and spectators, as there was now a physical separation between the two. The time allowed for each panel was found to be too long and was reduced from 20 seconds to 15 seconds

A variety of comic stories and backgrounds were tested. The comics were primarily three panels long, but several six and eight panel comics were 
tested. The comic stories were written by the researchers, and varied from simple dialogue, to popular culture references (including quotes from movies and internet memes), to excerpts from theatre productions such as Romeo and Juliet. The backgrounds were images found on the internet that were of a setting or scene without any subjects in the foreground. The backgrounds were matched to the theme of each comic story. For example, an image of an operating theatre was used as the background of a story about surgery.

The participants from both pilots enjoyed the simple dialogues but rejected those stories that they did not understand or were deemed not fun. Many popular culture references were not relevant to the participants and were removed. Participants explained that comics longer than three or four panels "felt too long" and were "boring" and were also removed or modified to be shorter. Excerpts from theatre were also negatively rated and were modified. The backgrounds were generally accepted and left unchanged.

An early prototype of Social Comics used a Vicon motion capture system to track the position of the players' heads in real-time so that the speech bubbles and their arrows would follow their associated character. Players wore hats fitted with reflective markers that were detected by an array of infrared cameras (Guo 2009). This fully implemented feature was added to enhance the artistic design of the comics by mimicking dynamic speech bubbles used in traditional paper comics.

The variety of props was reported to be limited in both pilots. Many props could not be used because they had reflective plastic components that interfered with the 3D motion tracking by creating unpredictable reflections. This created noise that temporarily broke the head tracking and correct rendering of the speech bubbles. The participants in the second pilot played half of the comics without the use of $3 D$ motion tracking. In this case, the speech bubble arrow was stationary and did not follow the players. The participants explained that this enhanced their gameplay because now they were free to use more props and did not have to swap the tracked hats if they wanted to change places in the comic. The 3D motion tracking was subsequently removed from the game.

\subsection{Revisiting the Design Framework}

Social Comics organically incorporates each of the gameplay elements discussed in Section 3: sociability, physicality and authorship.

The primary goal of the game is to create a comic strip and this is clearly established by the players with very little explanation. Two speech bubbles

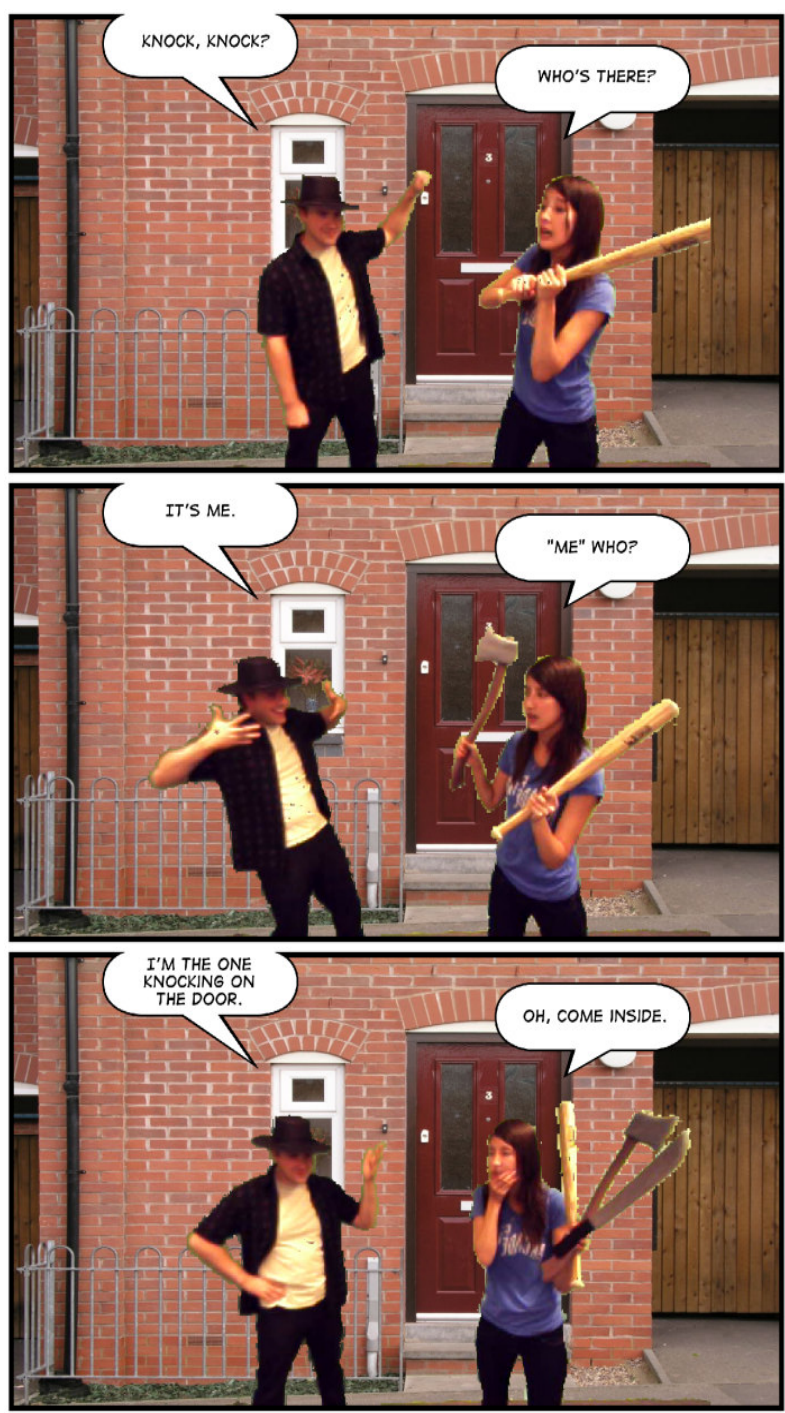

Figure 3: Final comic strip.

appear in every panel of the comic, suggesting that at least two people participate in the authoring process. The text in the speech bubbles gives the players room to explore their creativity while still providing structure to the game. There is also no restriction on other people joining the game or giving suggestions to the players. Finally, players must use their entire body to pose in the panels, and can use props and hats to change their appearance.

Each of the gameplay elements is necessary for the game to be effective and enjoyable. A lone person playing this game may get bored without any social interaction or feedback. Players may feel a lack of control if there is no camera or no direct feedback of their pose or of the physical props they are using. And finally, players may feel like they are wasting their time if they cannot save the content that they authored, or if the game does not record their creations. 


\section{EVALUATION}

We conducted an experiment to examine how groups of friends played Social Comics together. We were primarily interested in verifying if Social Comics is a fun game, and if emerging gameplay behaviours can be attributed to the gameplay elements that guided our design. Specifically we wished to evaluate if and how the new authoring element impacts the game experience. We were also interested in observing whether any social patterns would emerge during our evaluation, to see how the groups interpreted the comic text and props and to examine if people who do not normally play video games have fun playing Social Comics.

We wished to emulate a friendly and casual party atmosphere during the experiment similar to a real life gathering of friends. Each session was conducted with a group of four acquaintances. We did not organise the participants into groups but instead asked each participant to recruit three of their friends on our behalf. This would ensure that all members of the group were acquaintances and were comfortable with one another.

\subsection{Apparatus}

The study was conducted in an isolated room. This ensured that the sessions would not be disturbed by passersby and that it would not be disruptive to others, as the experiment was often noisy from laughter and conversation among the participants. The isolation of the participants helped ensure that they were free to play Social Comics as they wished, and would reduce any potential anxiety that may stem from strangers observing the gameplay.

The game was played on a Pentium 4 Windows PC and a Sony 60" LCD display facing a large green screen fixed to the opposing wall. The display and wall formed the boundaries of the acting space. Props were placed on either side of the display, easily accessible to the players but out of view of the webcam. The props included large handheld toys like a knife, shovel, baseball, and frying pan, smaller toys such as a stethoscope, frying pan, plastic drill, spatula, and ketchup bottle, as well as a variety of wearable hats (Figure 2). The hats were placed on a coat rack on the left of the acting space, and the handheld props were placed in a box on the right side of the acting space (as in Figure 1). The participants each sat in chairs placed to one side of the acting area so that the display was visible from each chair. The study administrator would sit several feet away and behind the chairs to minimise their impact on the gameplay.

\subsection{Full study}

We recruited eight participants with posted adverts and an email delivered to the electrical, computer, and software engineering email list. Each participant recruited three of their friends. Our study therefore included 32 participants; each was paid $\$ 15$ for participation in the study.

The experiment began by the participants signing consent forms and completing a questionnaire about how long they know their friends and how much time they spend playing video games with other people. Social Comics was then explained to the group and demonstrated by the administrator together with a volunteer from the group.

The group was then asked to play through fourteen unique comics together and each participant playing through seven comics. Each comic had three panels and 15 seconds were given to pose for each panel. Pairings were made randomly between the players in a round-robin fashion so that each player played through at least two comics with every other player. The administrator would explain the assigned pairings by giving directions about who was to play what comics at what time, but gave no further instructions on how the game should be played.

Once playing the comics was over, the participants completed another questionnaire about their enjoyment of the game, how they perceived the group behaved, as well as any additional comments about the experiment. Finally, an interview was conducted between the administrator and all the participants to address specific questions the administrator had after observing the session and to allow the participants to give their unstructured feedback about the experiment. The game sessions and interviews were filmed for transcription purposes.

\section{FULL STUDY RESULTS}

Eight groups performed the experiment. All of the participants were students whose ages ranged from 17 to 31 years $(M=21.2, S D=3.2)$. Overall, 28 per cent of the participants were female, and five groups had at least one female member, three groups being all male. From the questionnaires, 93 per cent of the participants reported that they knew all the other members in their group for at least six months. Seventy two per cent of the participants reported using a computer to play games (not exclusively), 62.5 per cent did not use a computer but only a console (Wii, Xbox, or PlayStation). Ninety three per cent of the participants reported using Facebook and check the website on average at least five times a day, as well as upload on 
average at least 25 photos to the site each month, mostly of social events and trips.

Several different qualitative gameplay patterns were observed regarding aspects of the game such as the use of props, backgrounds, poses, spectator involvement, and overall comic interpretations. Many of these patterns were explored during the interview portion of the experiment when the participants provided reflections and explanations of their behaviour.

In the discussion that flows, participants who are actively playing the game will be referred to as players (and their partners) and those who are sitting on the side and watching the players at a given time will be referred to as spectators. Direct quotes from a participant are shown in quotation marks a link to the participant identity is provided in parenthesis, for example (P7D) refers to participant D from group 7 .

\subsection{Time Restriction}

Most players expressed concern during the demonstration round when they were told that each panel should be completed in 15 seconds. Players often initially felt that it wasn't enough time. "At first I [thought] 'it's only 15 seconds?' but once you got into it and understood the concept then it was quite good." (P6D) Players and spectators warned each other when time was running out and they felt a pose or prop hadn't been properly selected. "Five seconds!" (P3B, spectating, and P3C, posing)

Some players felt that the time limit encouraged more creative gameplay, explaining that the game should be played rapidly and that the time restriction forced you to think and act quickly. "I think it was good, because part of the game was to think on your feet, so it never gave you too much time, but it was intentionally rushed." (P4B) "I thought the time was perfect, any longer and you over think it." (P7B)

One behaviour that was observed was players who would act their pose very quickly, during the first few seconds of a new panel being shown, and as a result they had to hold this pose while waiting for the timer to reach zero. "We have awkward moments. You know when we were trying to act the scene, and we have to hold the position, and then we can't stop laughing." (P1D) Two participants (P4A and P4C) broke their pose while they waited, returning to their pose only 2 seconds before the timer reached zero.

While many players did not feel constrained by the time limit, some raised concerns and said that they did not have enough time to create the kind of comic they had in mind. "It doesn't give us enough time to really set up a scene, if you have something in mind..." (P3A)

\subsection{Props}

After being introduced to the props in the demonstration round, the majority of participants incorporated props into every comic they acted in. Most of the props used by participants in the experiment were large toys like the shovel or baseball bat, as well as all of the hats. Many of these props had violent connotations and uses, and as a result the players often used them to simulate violence in the comics by posing as if they were fighting. "On the violent side." (P7A) Participants explained that the larger props were used more because they were easier to select and pick up due to their size, especially when the players were rushed for time. "The big ones are easier to use because you see them a lot better." (P4B) "Maybe if you laid them out instead of having them in the basket, [it] would be easier to see them all." (P4D)

Several players made sound effects related to the prop they were using, such as a crashing sound when swinging the baseball bat, or a chewing sound when holding the frying pan.

Most of the participants selected their props after the comic began, allowing them to read the speech bubbles in an attempt to match the prop to the text. Three of the groups (G4, G6, and G7) consistently selected their props before starting each new comic. These players would elaborately select their prop and hats, conferring with each other in order for their props to match one another's. "Alright, what are you picking?" (P7D asks P7A) When asked why they chose their props before the comic started, all three groups gave similar responses. "Sometimes it's funnier if you choose something and it doesn't work at all and you try to make it work." (P6C) If the players realised that the props they had selected did not match the text or background of the comic, they would often elect to keep the prop and to improvise a new use for it rather than try to find a different prop. "Since it's a game, and we're not trying to be serious actors, it's funnier to just keep going with what you started with [rather] than to try to make it look good." (P7C) Three participants were observed using their own personal artifacts as props. P5D and P7D each used their mobile phones, and P7A used a piece of paper and pen. Many participants expressed disappointment with the small variety of props but recognised the limitations of using too many different items. "Maybe a better variety [of props] would be good." (P7C) "But if you have more props, with 15 seconds time you have to search for them." (P2A) 
Furthermore, the use of props was not intuitive to all players immediately. Several participants weren't sure exactly how they should be used in conjunction with the panel text and backgrounds, if at all. "Well as we progress and play along, then we try to figure out what we can use the props for, but not at the beginning. It was the first time I played the game, so I was still trying to figure out which way is more entertaining." (P1D)

\subsection{Speech Bubbles and Backgrounds}

While opinions on the contents of the speech bubble text varied, participants generally agreed that they were very helpful and gave them an initial idea of how to interpret the comic story. "It gives you a guideline on what you're supposed to do." (P3C) One group explained that a critical element to the enjoyment from the game was that the text was already prepared for the players. "I think a game is more fun when you're following something, as opposed to making something up from scratch." (P3A) When the text appeared on the screen for the first time, the players (and also spectators) quickly read the text aloud, including their text and their partner's text. As the players posed for each panel, they read the lines as if reciting a play.

Participants explained that the textual story was given further context with the presence of a background and that it helped create a setting for the comic or to give the players an idea of the props they could use. "If there is a blank screen, we can't do anything." (P2A) "They [the backgrounds] kind of set the scene. And it makes it feel like what you're doing makes sense." (P3A) Players posed in specific locations so that their bodies would match and align with features in the background. For example, players made sitting poses in front of the green screen so that they appear to be sitting on chairs or tables in the comic, or pointing to items in the background. Players also aligned props with the background images, for example digging into the ground (background) with a shovel (prop), or repairing a car (background) with a drill (prop).

Participants were asked after the experiment if they wanted to jump into the game to join the players while they were spectators. Two common responses were reported. Some participants explained that they wanted to join in, but were afraid they would break the rules of the study or ruin the experiment. "I felt like I might ruin something in the study. [But] at a party, I'm pretty sure within the first two rounds, someone would join in." (P4C) "I didn't jump in because I thought it was the rules." (P7B) Other spectators pointed to the fact that there were only two speech bubbles shown in the comic strips, and that they didn't think they could find a place for themselves in the panel which was already occupied by two players.
"Because there were only two speech bubbles, you could join in if there were more speech bubbles." (P4C) "But I don't think you automatically want to jump in, because you see two text bubbles and you assume there's just two people in that scene. So I think even if you haven't made it structured, I don't think I would have jumped in. I would have just laughed, but I wouldn't have found a place in there." (P6B) Finally, some reflected that they could have embraced the lack of speech bubbles for themselves and could have treated the situation as a creative opportunity. "But actually, if you had said 'have three people' I would have definitely gone in. You could do some funny stuff with one person without a bubble." (P6C)

\subsection{Social Interaction}

We observed constant interpersonal interaction between all the participants (both players and spectators) for the duration of the game sessions. When the comic started, one of the players would usually take on a directing role to varying degrees. In the least assertive case, non-verbal suggestions were used. For example, if the dominant player motioned that they were hitting or pushing, their partner would react accordingly. More assertive dominant players would select props quickly and give verbal suggestions or explicit commands to their partner about their props and how to pose. "Here, use the stethoscope." (P7C hands prop to P7A) "Hold it out and point to it." (P4D to P4A) The most assertive dominant players sometimes motioned to their partner how to pose, or even physically moved the other player. "Swing it at me!" (P3D demonstrates swinging their arm to P3C who is holding a prop) "No, move closer to me P7A!" (P7D grabs and moves P7A) There were instances when both players were either dominant or nondominant. In the former case, the least observed, both dominant players would disregard the others' commands and pose how they wished. "You should hold it [a prop]." (P3A) "I'm going to do something else." (P3B) In the latter case, instances of two non-dominant players would sometimes result in lack of interaction between the players and even uncertainty to pose for the comic.

Generally, players displayed a range of implicit social behaviour such as mimicking the poses of their partner or spectators or reacting to the props their partner had chosen (P6C pretended their arm was missing when P6A picked up an axe prop). Players positioned themselves so that they are visible, facing the camera, and not blocking their partner, unless intentionally doing so. Players also verbalised their actions when it was unclear to their partner or to the spectators what they were trying to portray. "I'm coming at you with my vampire teeth!" (P7B simulates fangs with their fingers) 
The participants were asked if they felt engaged while being a spectator and not actively playing the game. Many reported that they were happy to take turns sitting out and that they felt like they were part of the game. "It's pretty funny to look at them acting." (P1A) "It gave you a chance to laugh at them. They're busy posing and trying to make it make sense, whereas you're just absorbing the final product." (P6D)

The spectators frequently gave suggestions to the players while they were creating their comic. This was usually in the form of simple suggestions about prop usage or positioning. "You're holding the drill upside down." (P7C) In other cases, the spectators gave explicit directions to the players. "You gotta bash the car." (P7D) "Yeah, bash!" (P7B) This was followed by praise when the players following the commands. "Well done, that was a good action shot!" (P7B) On some occasions, the spectators realised that they were directing the players. "Be like this." (P4D motions to P4A and P4B) "Look at you, 'director'!" (P4C)

Players often set challenges to the spectators when the two groups were switching roles, after the players finished their comic. This was usually in response to a joke or criticism made by the spectators while the players were making their comic. "Ok, be my guest." (P6C to P6A) "Let's see you guys take it up a notch." (P7D to P7B and P7C)

Socialisation occurred between the players and spectators after the comic was finished and while the complete strip was being reviewed on the screen. The creation of the comic and the associated entertaining moments were re-lived through re-reading the text or calling attention to humorous situations or actions the players created, with the spectators often praising the players for their efforts.

The participants were asked if they would consider playing Social Comics remotely with other players, if an internet multiplayer option was possible, for example. The participants reported that this type of game would not be fun to play online, citing the lack of social interaction as the primary reason. "No. This is a group thing!" (P3D) "I think the social aspect is the fun part, with your friends doing stuff. Online it wouldn't be the same." (P6A) "The social aspect is definitely one of the big points." (P7C)

\subsection{Playing with Strangers}

During the interview, participants were asked how they would approach this game if they were playing with strangers instead of their friends. Almost universally, the response was that the game may be very awkward at first but that the situation may become friendlier after a few comics were played together. "At the start it could be awkward, but at the end of the game it could be more friendly." (P2B) "I think it would be more reserved, because you'd be less comfortable with them in the beginning especially." (P6B) "I think if you'd really wanted to play, you'd eventually work with a stranger. Eventually you'd become comfortable enough to work together." (P6D) "It would probably be a little more awkward if we didn't know each other as well as we do." (P7C)

\subsection{Sharing the Comics}

Finally, the participants were asked if they would share the comics with their friends by uploading them to blogs or social networking sites. Many participants were open to this, but specified that they would only share the comics that they liked or thought were entertaining. "It just depends on how funny it was. If it was something that you didn't feel good about, or was kind of stupid, you could leave it out. But if you got a laugh out of it, for sure [upload it]." (P4B) "Some of the funnier ones where we're making those faces and being silly. That's funny, people would like to see that. It's good entertainment." (P7C) "I see it [uploading] as a big benefit of the game, so you can share whatever funny thing that you came up with, to include more people." (P3A)

\section{DISCUSSION AND FUTURE WORK}

The results of our study reflected on the social, physical, and authorship gameplay elements in Social Comics, verified their value and strengths, as well as revealed some of the current design limitations and points for improvement. We were glad to see that the gameplay observations demonstrated strong social interaction among all the participants, both spectators and players. The participants generally made extensive use of the props and created unique and creative poses for the comics.

We also noticed variations in the style of gameplay and attributed this to how the participants treated Social Comics. Some saw it as a rapid fire game that makes you think on your feet and emphasizes improvisation and quick reactive playing. This approach favoured bizarre poses and prop selections, often disregarding the contents of the speech bubbles and even backgrounds. Players tried to be as entertaining as they could to themselves and their spectators. Others approached the game like a creative tool that lets you build a comic with your friends. These players appeared to incorporate relevant props and attempted to create poses that carefully matched the comic story and background. However, the social, physical, and authoring qualities of the game generally did not change between the two 
gameplay styles, demonstrating that Social Comics can be played in more than one style while still being fun.

We were pleasantly surprised to learn that the participants believed Social Comics could be played successfully with strangers. This inspired a current and future exploratory study involving two groups of two participants. While the two participants in each group are friends, they do not know the people in the other group. We are curious to learn if this condition would still be fun to play, and whether the groups would complete the experiments with a closer and more intimate insight of the players they did not know before playing Social Comics.

Participants provided many suggestions on how to improve the game. The most popular request was the ability to customize the comic by writing your own text, creating your own backgrounds, and downloading stories that other players have created to keep the game spontaneous. Playing the game with blank speech bubbles and writing into them after the comic was complete was also requested, as well as moving the speech bubbles around. Players wanted a larger variety of props and comic stories, including stories with three speech bubbles. Non-static and interactive background images were requested several times, as well as chairs or tables that were green, so that players could sit and align themselves with the background. We are hoping to explore these features further in future prototypes of Social Comics.

\section{CONCLUSION}

In this paper we present Social Comics, a computer game that allows players to participate and interactively author comic strips in which they are the main characters, acting according to the text in the speech bubbles and backgrounds.

We reflect on our design approach for Social Comics through our vision for the future of video games that include gameplay elements based on sociability, physicality, and authorship. Specifically, we emphasise the uniqueness of authorship where creating new content becomes an important and enjoyable gameplay challenge for players.

Our paper details the implementation of Social Comics, and how the game allows players to participate in live comic strip creation and in interactive authorship of new content. We discuss an extensive user study we preformed in an attempt to evaluate Social Comics, to consider the impact of the gameplay elements that guided its design, and to better understand how to improve the game in its future versions.

We see Social Comics as a case in point reflecting on the future of a genre of video games that will be focused more and more on providing players with gameplay experiences that are based on sociability, physicality, and authorship, enhancing the player experience, and making the game more engaging and fun for a group of players and spectators.

\section{REFERENCES}

Chaplin, D. J. (1993) Chroma key method and apparatus. U.S. Patent No. 5249039, Washington, DC: U.S. Patent and Trademark Office.

Entertainment Retailers Association. (2011). ERA Yearbook 2011: UK Statistics.

http://www.eraltd.org/downloads/stats/GamesMark et.pdf (retrieved 04 May 2011).

Entertainment Software Association. (2010). 2010 sales, demographic and usage data: Essential facts about the computer and video game industry. http://www.theesa.com/facts/pdfs/ESA_Essential_F acts_2010.PDF (retrieved 24 January 2011).

Guo, C., Young, J. E., and Sharlin, E. (2009) Touch and toys: new techniques for interaction with a remote group of robots. Proc. of the 27th intl. conf. on Human factors in computing systems, Sept. 2009, 491-500. ACM Press, New York, NY.

Lapides, P., Sharlin, E., and Costa Sousa, M. (2010) Creating social, physical, and authoring games. 3rd Annual Intl. Conference on Computer Games Multimedia and Allied Technology, Singapore, Singapore, April 6- 7, 2010.

Rowland, D., Durrant, A., Fischer, J., Kirk, D., Benford, S., and McAuley, D. (2010) "Automics": assisted mobile authoring of photostories as souvenirs of a day in the park. Digital Futures, Crowne Plaza, Nottingham, October 11 - 122010.

Sall, A. and Grinter, R. E. (2007) Let's Get Physical! In, Out and Around the Gaming Circle of Physical Gaming at Home. Computer Supported Cooperative Work, April 2007, 199-229.

Voida, A. and Greenberg, S. (2009) Wii all play: the console game as a computational meeting place. Proc. of the 27th intl. conf. on Human factors in computing systems, Boston, MA, September 4 - 9 2009, 1559-1568. ACM Press, New York, NY.

Yoostar 2 (2011), Yoostar, http://ys2.yoostar.com/ (retrieved January 24, 2011) 